\title{
O PAPEL DO PROCESSO NA CONSTRUÇÃO DA DEMOCRACIA: PARA UMA NOVA DEFINIÇÃO DA DEMOCRACIA PARTICIPATIVA
}

\section{THE ROLE OF THE PROCESS/CASE IN BUILDING DEMOCRACY: FOR A NEW MEANING OF PARTICIPATORY DEMOCRACYS}

\author{
Darci Guimarães Ribeiro" \\ Felipe Scalabrin
}

\begin{abstract}
Resumo: A democracia está em crise, não mais nos sentimos representados, não mais o povo é invocado de maneira autêntica, ora é mero ícone, ora é apenas faceta do que deveria ser um todo. Necessário um novo pressuposto, calcado em possibilitar o máximo desenvolvimento das garantias individuais e de assegurar que o Estado cumpra suas funções constitucionalmente estabelecidas. É a participação irrestrita que caracterizará a democracia participativa, mesclando-se com o amplo acesso ao Poder Judiciário - que surge no cenário democrático como autêntico protagonista. Nessa senda, como meio de inclusão de qualquer cidadão, o processo adquire relevo em seu aspecto político (para além do jurídico), como instrumento que possibilita ao juiz avaliar os múltiplos interesses hierarquizados pela sociedade e, por fim, dar vida ao direito, concretizando, assim, o pressuposto democrático.
\end{abstract}

Palavras-chave: Cidadania. Democracia. Judicialização. Participação. Processo.

\begin{abstract}
Democracy is in crisis. We no longer feel represented, no longer is the people summoned in an authentic way; it is now a mere icon; it is now only a facet of what should be a whole. Now a new assumption is needed, based on enabling maximum development of individual guarantees and ensuring that the State fulfills its constitutionally established functions. It is the unrestricted participation that will characterize participatory democracy, together with broad access to the Judiciary Power - which comes in the scenario as a real democratic leader. In this way, as a means of inclusion for all citizens, the process/case takes a political role (beyond the law) as a device that allows the judge to assess the multiple interests that are hierarchically set by the society and, finally, to bring law to life, thus making democracy real.
\end{abstract}

Key-words: Citizenship. Democracy. Judicialization. Participation. Process/Case.

Doutor em Direito pela Universitat de Barcelona. Professor Titular da Unisinos e do Programa de Pós-Graduação em Direito - Mestrado e Doutorado. Professor Titular da PUC/RS. Advogado. Membro do Instituto Brasileiro de Direito Processual Civil. Membro representante do Brasil no Projeto Internacional de Pesquisa financiado pelo Ministério da Educação e Cultura - MEC - da Espanha.

Email: darci.guimaraes@terra.com.br

"Bolsista voluntário no projeto Democracia, Participação e Processo: A concretização da democracia participativa através do Poder Judiciário. Email: fscalabrin@gmail.com 
"O povo inglês pensa ser livre e engana-se. Não o é senão durante a eleição dos membros do Parlamento. Uma vez estes eleitos, torna-se escravo e nada mais é". (ROUSSEAU, 1978, p. 132).

\section{INTRODUÇÃO}

As linhas que seguem têm por escopo uma análise jurídico-política acepção dada por Calmon de Passos (1999, p. 70) - da democracia vigente com vistas a proporcionar, ainda que de maneira singela, uma nova alternativa para o florescimento de um espírito participativo do indivíduo na concretização da democracia contemporânea. Iniludível que o ente estatal se tipifica, hodiernamente, não só pelo adjetivo (Estado) de direito ${ }^{1}$, como também, pelo seu viés democrático. Dessa maneira, deve o Estado propiciar que a cidadania, elemento essencial da democracia, seja exercida em sua mais ampla plenitude. Contudo, cabe ao próprio cidadão ativo (ARENDT, 1990) pressionar as instituições para concretizar seus interesses.

Nessa perspectiva, surge o juiz como ator determinante na efetiva criação do direito e na solução das legítimas pretensões sociais, de sorte que a própria democracia se realiza quando resolvido o caso apresentado ao Poder Judiciário.

Para melhor esclarecer os meios através dos quais tal premissa se torna factível, necessário uma releitura da definição do adjetivo democrático, trazendo a tônica para o cidadão - e não apenas para o povo - e, com isso, penetrar nos meandros processuais, onde as garantias constitucionalmente previstas dão ao individuo meios de assegurar que ele se confronte com o posto e busque um aprimoramento do debate democrático. Mais que isso, necessário fazer a distinção entre democracia participativa e democracia representativa para enfim podermos evidenciar que a representatividade já não é mais capaz de sozinha

\footnotetext{
${ }^{1}$ Acerca do Estado de Direito a literatura constitucional é profícua, porém, convém destacar para um melhor aprofundamento as obras de: COSTA, P.; ZOLO, D. O Estado de Direito. Trad. por Carlos Alberto Dastoli. São Paulo: Martins Fontes, 2006, especialmente as introduções, p. 3 a 198; REIS NOVAES, Jorge. Contributo para uma teoria do Estado de Direito. Coimbra: Coimbra, 1987, especialmente os cap. II e VI; BIDART CAMPOS, German José. Doctrina del Estado Democrático. Buenos Aires, EJEA, 1961, especialmente os cap. I e IV; CANOTILHO, J. J. Gomes. Direito Constitucional. 5o ed., Coimbra: Almedina, 1992, parte IV, especialmente os cap.I a III; Estado de Direito. 1ํo ed., Lisboa: Gradiva, 1999; REALE, Miguel. O Estado Democrático de Direito e o conflito das ideologias. São Paulo, Saraiva, 1998, especialmente os cap. I, II e IV; STRECK, Lenio L. Jurisdição constitucional e hermenêutica: uma nova crítica do direito. $2^{\underline{0}}$ ed., Rio de Janeiro: Forense, 2004, especialmente os cap. I a IV,
} 
realizar o autêntico ideário democrático, tão aspirado para a realização de uma sociedade justa e solidária.

Estabelecidos estes parâmetros mínimos acerca da forma do Estado, nos debruçaremos sobre a concretização desta através do processo judicial, entendido este como o meio pelo qual os direitos e as garantias constitucionais concretizados no ato criativo do juiz são determinantes para a persecução de uma identidade democrática do Estado.

\section{PRESSUPOSTO DEMOCRÁTICO: O POVO}

Quando entramos no discurso democrático, o primeiro termo aberto é o povo. Não há dúvida que tal elemento deve integrar o conceito de democracia, na medida em que a própria palavra nasce para referi-lo. Tanto é assim que a palavra democracia deriva do grego “démokratía, de dêmos 'povo' + kratía, 'força, poder' (do v.gr. kratéó 'ser forte, poderoso')”. Por outro lado, a primeira referência a este termo está em Tucídides (2000), colhida na oração fúnebre de Péricles aos atenienses mortos na guerra do Peloponeso:

Tenemos un régimen político que no emula las leyes de otros pueblos, y más que imitadores de los demás, somos un modelo a seguir. Su nombre, debido a que el gobierno no depende de unos pocos sino de la mayoría, es democracia. [...]. (ESBARRANCH, 200, p. 342).

Contudo qual o papel do povo no discurso democrático? Seria o pressuposto para atuação do Estado? Seria ele mero símbolo para validar o discurso da democracia? Com singela originalidade, mas com extrema profundidade, indaga Friedrich Müller, afinal, quem é o povo?

Segundo o filósofo alemão, muitas são as definições possíveis de povo pensamento, aliás, partilhado por Kelsen (2000, p. 36-40) - razão pela qual faz uma proveitosa cisão conceitual acerca do termo: povo como meio de legitimar o Estado, povo-ativo (participante das decisões políticas); povo como instância global de atribuição de legitimidade, povo-ícone; e o povo como destinatário das decisões e atuações públicas. Para os fins do presente trabalho interessa-nos aqui apenas o último termo, contudo, nos é impossível adentrarmos nele sem antes permear, mesmo que perfunctoriamente, os demais significados.

Convém destacar, inicialmente, que a maioria das constituições modernas menciona a palavra povo como pilar de sustentação do Estado Democrático. Isto é, o Estado Democrático de Direito busca sua justificação - pretende sua legitimação - a partir do povo (MÜLLER, 2003, p. 50). Nessa perspectiva, tal definição de povo o enquadra na célebre frase de Lincoln - the government 
of the people - na medida em que o governo está instituído por ele o povolegitimador. Tal povo não é palpável, mas verificável apenas como fonte de validade do poder estatal.

Por outro lado, aquele que irá ditar os caminhos do Estado, no que tange às suas estruturas políticas vigentes, é o denominado povo-ativo. Aquele que se constitui no legítimo destinatário dos direitos políticos e tem soberanamente a prerrogativa de, tempo a tempo, alterar os que representam seus desidérios através do processo eleitoral (MÜLLER, 2003, p. 55-7). Enfim, povo ativo é o titular dos direitos políticos e aquele que possibilita o governo do povo, the government of the people, le gouvernement du peuple.

Porém, o mais presente povo é o mais sorrelfo deles. É aquele que é invocado, mas que nunca se vê. É aquele cuja legitimidade não se faz presente no sistema. É o denominado povo-ícone. E se traduz naquela imagem de povo que é verbalizada pelos seus representantes e cujas decisões não são atribuíveis ao próprio povo em termos de direito vigente, mas, tão somente como palavra vã de falsa legitimidade. Em outros termos, se é o povo quem dita os critérios de escolha e decisão do Estado - que deverá sempre agir em consonância com o ordenamento jurídico - então toda a resolução estatal deve subsumir-se aos textos democracticamente postos e, em não o fazendo, teríamos o uso da palavra povo como meio para tornar válido algo que na origem não o é.

Ora, se há um povo legitimador (ativo), se há um povo deslegitimado (ícone) e se há aquele povo pelo qual se funda o próprio Estado, deve se fazer presente, também, o povo para o qual se erige o Estado. Eis aí o povo-destinatário, que diversamente dos outros, deve ser entendido sem restrições. $O$ povo destinatário é compreendido em todo cidadão pelo qual o corpo social passa a ser responsável, é o rule for the people. Enquanto o povo-ativo é restrito, o povo-destinatário não o é, pois sobre ele recai todos os deveres positivos (prestação) e negativos (não interferência) do Estado, na medida em que atribuíveis a todo e qualquer indivíduo ou que nele se encontre inserido.

A análise feita por Friedrich Müller dos diferentes modos de se conceituar a palavra povo revela-nos que quando da aplicação do direito e da tentativa de efetivação do Estado Democrático, há uma plena confusão entre os muitos destinatários da democracia. Ocorre que as estruturas do sistema acabam por assegurar direitos apenas a determinados tipos de povo, ora povo-ativo ora povo-ícone, contudo esquece-se que a democracia é, acima de tudo, feita para todos e que mesmo que não seja construída por todos (e.g., inc. I e II, do art. $14 \mathrm{da}$ CF) deve, obrigatoriamente, ser exercitável por todos. Não é sem rumo que temos presente em nosso ordenamento o acesso irrestrito ao Poder 
Judiciário, segundo se depreende do inc. XXXV, do art. 5o da CF. Através deste direito fundamental, as incompatibilidades existentes no meio social se tornam resolúveis e todo indivíduo tem a potencialidade de ser ouvido e ter sua causa satisfatoriamente atendida.

Não basta pensarmos no aprimoramento da democracia apenas na perspectiva da exclusão social que busca inclusão, muito menos nos movimentos sociais da minoria. Estes representam, em última análise, apenas uma faceta do povo-destinatário, e este último deve compreender tanto os excluídos, como também os ativos, aqueles que votam e aqueles que se engajam nas decisões do Estado, compreendendo, enfim, todo cidadão-indivíduo que se encontra no território do Estado, ou como quer o professor de Heidelberg, "o povo enquanto destinatário das prestações estatais negativas e positivas, que a cultura jurídica respectiva já atingiu” (2003, p. 100).

De todo o exposto anterior, podemos concluir que enquanto o povo servir de baluarte para arbitrariedades estatais ou apenas para tentar legitimar atitudes manifestamente contrárias aos interesses constitucionalmente resguardados e que se manifestam em concreto diante do ato jurisdicional instrumentalizado pelo processo, não teremos uma democracia condizente com o enunciado no texto constitucional. Portanto, na mesma medida em que o acesso à justiça é amplo, ampla também deve ser a definição de povo em um verdadeiro Estado de Direito que pretende ser legitimamente Democrático.

\section{PARTICIPAÇÃO E DEMOCRACIA}

O vértice da democracia ainda é o povo, contudo dilatado em sua acepção originária. Este ideário de povo deve, necessariamente, ser compreendido em qualquer indivíduo que seja sujeito de interesses juridicamente tutelados ${ }^{2}$, protegido pela possibilidade de apreciação de seus conflitos e, preponderantemente, como novo partícipe na realização concreta da seara política. A partir daí, observaremos que não se pode mais mirar a democracia

${ }^{2}$ Deve-se ter presente que o ordenamento jurídico traz a tona apenas o direito objetivo, ou seja, hierarquiza os interesses das pessoas em sociedade. Acerca dessa complexa distinção que atribui ao direito objetivo uma dupla função, psicológica e judicial, vide RIBEIRO, Darci Guimarães. La pretension procesal y la tutela judicial efectiva: Hacia una teoria procesal del derecho. Barcelona: Bosch, 2004, especialmente p. 28-35. Esta idéia encontra-se melhor desenvolvida no artigo intitulado Esboço de uma teoria processual do direito. In: Constituição, Sistemas Sociais e Hermenêutica: Programa de Pós-Graduação em Direito da Unisinos: Mestrado e Doutorado. Porto Alegre: Livraria do Advogado, 2008, p. 53-64. 
unicamente sob a perspectiva procedimental, como pretendia certo autor italiano, posto que ela vai muito além do mero voto nas urnas a cada período eleitoral determinado e tampouco importa na simples manutenção das regras do jogo (BOBBIO, 2006, p. 30, 77-95), já que é dinâmica e se recria diariamente pela práxis.

Com efeito, se em dado período histórico a democracia representativa teve sua chance de ascensão, tanto em razão de específicas contingências históricas como a pressões de um ideário calcado no Liberalismo (BOBBIO, 1998, p. 53) e, inclusive, se consolidou como ápice das formas de Estado, agora ela se apresenta em derrocada, pois já não é mais capaz de "cumprir suas promessas", tampouco de representar o povo e muito menos de subsumir o povo que tanto ela invoca. Por isto, podemos concluir, parafraseando Roberto Amaral (2003, p. $26,32)$, que "a democracia representativa está prostrada em seu leito de morte, incuravelmente corroída pela ilegitimidade".

Deste modo podemos facilmente afirmar que a democracia participativa é a verdadeira democracia do Terceiro Milênio, onde o adjetivo participação passa a ser o novo referencial em termos democráticos, inserção da (re)qualificação do povo, para além de mero ícone, catapultando-o, assim, para o cenário democrático como ator principal e não mais como mero coadjuvante, como aquele que está apto de fato a reivindicar sua posição proeminente em uma sociedade livre, solidária e justa (Bonavides, 2003, pp. 281-96). Conseqüentemente, a legitimidade da democracia, de acordo com Goffredo Telles Júnior (2003, p.

${ }^{3}$ Bobbio (1998, p. 34-45) elenca magistralmente as seis promessas não cumpridas pela democracia representativa: a) a vontade geral como centro de poder - a realidade social demonstrou que não existe apenas um foco de força política, como pretendiam os idealizadores da democracia, de sorte ser impossível alcançar uma única vontade geral, já que efetivamente existem, de fato, diversos núcleos de poder que coexistem; b) contenda de interesses - o representante deveria apenas buscar os interesses de toda a coletividade, mas, de fato, busca os interesses daqueles que o colocaram no poder; c) a manutenção das oligarquias; d) o espaço limitado - apesar de ser agora ampla a quantidade de votantes, seu espaço de inserção no discurso político ainda é ínfimo, daí a crise estar em "onde se vota?", ou seja, em definir quais os momentos em que o povo é efetivamente chamado a se manifestar sobre determinado tema; e) a persistência de um poder invisível - a noção de que existem, ainda, instituições e órgão que agem nas sombras, sem publicizar seus atos, atuando com intenções duvidosas; e, por fim, f) o problema da cidadania - o cidadão, a partir da possibilidade de atuar através da democracia, aprenderia, e se transformaria em um cidadão ativo e participante, que se engajasse na prática política - o que não apenas não aconteceu como se procedeu ao inverso: as democracias mais consolidadas têm por característica um povo apático e desinteressado. 
70), "depende da introdução da vontade dos governados nas decisões e nos atos dos governantes".

Nessa perspectiva, não se prega o ocaso da representatividade, mas sim um aprimoramento, um refinamento do que está posto, para melhor atender ao indivíduo em sociedade, mantendo assim sua verdadeira identidade social. Afinal, a democracia participativa seria a forma mais evoluída das quatro fases do desenvolvimento da democracia que, segundo Macpherson (1978), se iniciou com a fase protetora, posteriormente veio a fase do desenvolvimento, seguida da fase do equilíbrio, para então culminar com a fase participativa.

A transição da forma representativa para a participativa certamente se dará de maneira gradual, pois quem nunca aprendeu a ter papel ativo em sociedade dificilmente conseguirá esta árdua façanha simplesmente pelo fato de agora existirem mecanismos legais de participação. É necessário para isto um longo trabalho educativo de, quem sabe, gerações.

Democracia e participação, nesta perspectiva, se fundem em um conceito unívoco, incindível, capaz de traduzir a um só tempo a exata compreensão da soberania popular. Democracia participativa constitui, nas exatas palavras de Roberto Amaral (2003, p. 48), "uma tautologia virtuosa”.

\subsection{Democracia Vigente}

Fruto dos ideários pós Revolução Francesa, a democracia que conhecemos em muito pouco se assemelha com a democracia grega, base do pensamento iluminista-montesquiano, criador da democracia representativa, que é teleologicamente formal. Apesar de nem mesmo Péricles ter visto tão longe como Rousseau (em seu contrato social), as idéias do filósofo de Genebra jamais foram totalmente concretizadas, seja por desinteresse político, seja por impossibilidade concreta. Enquanto isso, a democracia da civilização helênica teve sua parcela de contribuição: basta referirmos que, na ótica grega, apenas detinham direitos políticos os cidadãos, enquanto o restante do povo não se envolvia nas questões políticas. Da mesma forma, o primeiro ponto do pensamento instituidor da democracia representativa foi delimitar os indivíduos que estavam aptos a votar - fenômeno que ocorreu tanto na França como nos Estados Unidos.

Fato é que na revolução Francesa quando o poder absoluto do rei foi repudiado, a nova classe dominante - burguesia - necessitou buscar seu próprio instrumento racional de legitimidade, e o fez através da utilização do povo, já que gozavam de imenso prestigio em sociedade - não foi à toa que os membros da Revolução criaram seu povo-ícone, também para tornar válida suas ações - e, concretamente, não era possível a tomada de decisão por todos os indivíduos 
da sociedade. Sugeriu-se, então, a representação destas pessoas por outras legitimamente eleitas, já que a burguesia enunciava e defendia o princípio da representação. E, de acordo com Bonavides (2004, p. 43), "do princípio liberal chega-se ao princípio democrático. Do governo de uma classe, ao governo de todas as classes".

A idéia foi realmente um verdadeiro sucesso, tanto que encontramos ainda hoje esta forma de legitimidade social. Modernamente esta idéia ainda configura o ideal de democracia, razão pela qual o Estado Liberal floresceu. Porém, a cisão entre o âmbito político e o âmbito econômico (CALMON DE PASSOS, 1988, p. 90) representada pela livre dominação do mercado nas relações e pela participação mínima do Estado entre os indivíduos, levou tal forma de governo à ruína. Assim, o Estado assume novamente novos compromissos e reata o rompimento anterior fazendo com que o político e o econômico voltem a se coaptar.

Observa-se que o Estado - agora intervencionista - se torna o inverso de seu antecessor liberal e adquire bases e diretrizes complexas voltadas à reestruturação de um sistema já em crise (STRECK; MORAES, 2004, p. 92), possibilitando a assunção de uma função social - notadamente observada nas constituições Mexicana e de Weimar. Surge assim a noção de justiça social e, principalmente, o alargamento dos poderes políticos do indivíduo.

Nesse mesmo período, o papel da democracia passa a ganhar contornos mais definidos, acertando Bonavides (2003, p. 157), ao referir que ele - Estado Social - é o mais apto a consagrar os valores do sistema democrático, pois segundo o autor:

Esta espécie de Estado social, humanizador do poder, jurídico nos fundamentos sociais da liberdade, democrático na essência de seus valores, padece, de último, ameaça letal à conservação das respectivas bases e conquistas. Esmaecê-lo e depois destruí-lo é parte programática das fórmulas neoliberais propagadas em nome da globalização e da economia de mercado, bem como da queda de fronteiras ao capital migratório, cuja expansão e circulação sem freio, numa velocidade imprevisível, contribui irremissivelmente para decretar e perpetuar a dependência dos sistemas nacionais, indefesos, e desprotegidos, sistemas que demoram nas esferas do Terceiro Mundo.

Portanto, observamos que a inclusão do cidadão, em tese, deveria ter aumentado durante o período subseqüente ao Estado Social, porém a realidade demonstra exatamente em sentido contrário. Mesmo com o aumento dos direitos políticos, com o crescimento do povo-ativo, ainda assim, poucos são os indivíduos que, ao observar as ações do Estado, se sentem ali representados. Decisionismos, processos legislativos incoerentes e obscuros, aumento exacerbado do uso de Medidas Provisórias, enfim, nos encontramos diante da 
falência institucional dos poderes executivo e legislativo, justamente os que mais deveriam estar próximos ao cidadão, tendo em vista o seu imenso respaldo eleitoral, mas, em realidade, eles se encontram os mais distantes (BONAVIDES, 2003, p. 281-96).

Mais que isso, o recente cenário político demonstra uma crise ética sem precedentes na história da nossa sociedade ${ }^{4}$. Como então é possível dar concretude à democratização da sociedade e do Estado mantendo ainda as desigualdades e preservando as clássicas prerrogativas individuais, especialmente de um determinado grupo de pessoas? Neste momento conturbado da história, é necessário voltar a atenção para outro ator, tão ou mais legítimo do que os outros, inobstante não gozar da falácia da legitimidade popular, consubstanciada no voto, qual seja, o Poder Judiciário.

Destarte, a democracia participativa avulta para destacar o papel não só de maior inserção do indivíduo nas escolhas administrativas e legislativas, mas também e principalmente a partir do âmbito judicial, pois o acesso ao poder judiciário é irrestrito, bastando lesão ou simples ameaça a direito para que este abra suas portas ao cidadão, ao povo - assumindo este a conotação ampla anteriormente exposta. Esta abertura, por assim dizer, cria para os indivíduos em sociedade a possibilidade de exigir do Estado a concretização das promessas ainda não realizadas e que dificilmente o serão através do Executivo e do Legislativo. Nesta perspectiva o processo passa a ser um valioso instrumento público posto a serviço do povo para viabilizar a essência da democracia que está configurada nos direitos e garantias fundamentais.

\subsection{Democracia Participativa e Processo como Instrumentos de Concretização da Democracia}

O discurso acerca da democracia participativa tem sido direcionado às minorias e à inclusão social em termos eminentemente sociológicos. Tanto é assim que, ao mencionarmos o termo democracia participativa logo se torna presente conceitos como "orçamento participativo" e "fórum social", ou seja,

\footnotetext{
${ }^{3}$ Inobstante citarmos essa perspectiva de crise, devemos assumir, de igual modo, que a sociedade sempre se encontra imersa em determinadas crises, que devem a todo modo ser confrontadas e superadas, pois, de acordo com Ovídio Baptista (1988, p. 99): "Não há sociedade humana isenta de crise, assim como não se pode conceber a história sem transformações e mudanças sociais permanentes. Sobre isto, aliás, disse um ilustre filósofo contemporâneo 'Por isso mesmo as épocas de crise - aquelas, precisamente em que o sistema cede lugar ao problema - são épocas de maturidade e de autenticidade espiritual'”.
} 
assume-se como ponto de partida que a inclusão do cidadão na gerencia do múnus público deve ocorrer no campo estritamente administrativo das escolhas e nas escolhas propriamente ditas.

Daí se dizer que a participação propiciada ao cidadão através de programas como o orçamento participativo desvela-se na atuação individual ante o Poder Executivo. Dizendo de outro modo, tais mecanismos respondem ao problema da crise da democracia representativa, simplesmente permitindo ao cidadão uma inclusão em apenas um dos poderes constituídos - e ainda assim, duvidosa esta forma de participação e mais curiosa é a execução dos planos, que atuariam em cima de escolhas pré-determinadas?

Por outro lado, o discurso acerca da democracia participativa também é desenfocado quando mira o Legislativo. Infelizmente a representação, como já constatado, e nos moldes em que existe, é pura ficção, engodo criado exclusivamente para legitimar as atitudes de um parlamento corrupto e servil do Executivo. Porém, dessa falsa representatividade nasce uma dissonância total entre as decisões do parlamento e a suposta vontade popular. A alardeada soberania popular dos representantes, que a muito está em crise, abre espaço a novos mecanismos legislativos - que, desde Kelsen (2000, p.117) já se referenciava - as como o referendo, o plebiscito e a iniciativa popular. Todos previstos constitucionalmente, mas de rarefeita eficácia, basta analisar nestes vinte anos de constituição quantas vezes nos valemos deles?

De igual modo, Paulo Bonavides (2003, p. 36) que por inúmeras vezes já defendeu a participação do povo, define que a democracia participativa possibilita o direito à resistência e à luta. Aqui, o legitimador do sistema, o norte da estrutura, deixa de ser a lei. Não se olha mais para o Estado, mas sim para quem o irá compor em última instância, ou seja, o próprio cidadão. Com base nisto, afirma o autor: "consiste a essência e o espírito da nova legitimidade: o abraço com a Constituição aberta, onde, sem cidadania não se governa e sem povo não se alcança a soberania legítima”. Deverá se observar que a lei se constitui em mera baliza de interpretação donde se deve operar a concretização dos direitos que, hoje, são restringidos ao plano abstrato normativo. Não há interpretação sem escolha política, contudo, esta deve ser uma política de concreção dos valores inseridos na Constituição.

Portanto, para além da democracia participativa inserida nos âmbitos já citados, devemos concebê-la em seu aspecto verdadeiro: aquela visão de democracia em que o indivíduo está concretamente engajado na busca daquilo que ele entende ser o melhor para si e para a sociedade em que vive, ele é o verdadeiro protagonista dos rumos da sociedade e não mais os seus representantes. 
É ele, e somente ele, que sabe o que é melhor para si e, conseqüentemente, para os outros. Não há transferência de legitimidade a outros, pois só transfere legitimidade, num regime verdadeiramente democrático, quando não se é capaz de, por si só, concretizar a realização de uma sociedade livre, justa e solidária.

Nesta perspectiva, o Judiciário está em franca vantagem para a implementação da democracia participativa, porquanto é o mais legitimado das três funções do Estado para realizar as promessas da modernidade. Como se o povo ativo escolhe seus governantes: legislativo e executivo? Onde estaria a legitimidade democrática do Judiciário, que não é eleito nem escolhido por esse ator decisivo que é o povo? Sua legitimação decorre não do sufrágio universal como nas outras esferas de poder, mas de uma legitimação procedimental que encontra no irrestrito acesso ao judiciário, no contraditório, na publicidade e na fundamentação os mais altos desígnios da legitimidade democrática, pois é através do processo, como garantia constitucional do Estado Democrático de Direito, que o direito é realmente criado (RIBEIRO, 2008, p. 63-4) e não a lei (GROSSI, 2003, p. 21). Sem falar no grau de credibilidade social que usufrui o Judiciário quando comparado ao Executivo e ao Legislativo, pois é o mais ético deles.

Nesta ordem de idéias podemos citar Friedrich Müller (2003, p. 56), para quem:

No Poder Executivo e no Poder Judiciário a "dominação" do povo ativo pode ser vista operando de forma mediada, na medida em que prescrições capazes de justificação democrática estão implementadas em decisões de maneira correta em termos de Estado de Direito, no sentido de capazes de universalização e de recapitulação plausível (überzeugend nachvollziehbar).

Até mesmo Boaventura de Sousa Santos (2002, p. 43-50), que tanto defende a democratização através dos movimentos sociais e do que ele denomina emancipação social das minorias ante as camadas hegemônicas da sociedade concorda que, no Brasil, o Estado muito promete e pouco cumpre, assim, o Judiciário assume relevância ímpar. Por vezes, seguindo o pensamento do autor, irá ocorrer de o Magistrado substituir o sistema da administração pública através de sua decisão, de sorte que este realize o ato que deveria ter sido espontaneamente praticado pela administração - e nesse sentido é clássico o exemplo dos medicamentos (SANTOS, 2007, p. 19).

De fato, não são poucos os conflitos entre os indivíduos e o Estado que não cumpre com seus deveres. É aí que entra o Judiciário para concretizar estas promessas não cumpridas, efetivando, assim, a execução destas prestações, como refere Boaventura de Sousa Santos (2007, p. 23):

Ora, no momento em que os tribunais começam a julgar para cima, em que começam a incriminar e a julgar grandes empresários ou membros de classe 
política a situação muda. É nesse momento que se dá aquilo que eu designo por judicialização da política”.

Apesar dessa necessidade imediata de mudanças, de uma exigência social por maior efetividade e de um acesso à justiça no presente, como quer Ovídio Baptista (1988, p. 113), a democracia ainda pressupõe muito. Ela clama no plano político por acesso à informação e por uma consciência do eleitor para saber em quem se vota e porque se vota.

A relação da democracia como instituição do Estado de Direito, aliada a uma permanente práxis, pode muito bem ser resumida nas palavras de Moreira Neto (1992, p. xvii), para quem:

A democracia, enquanto conjunto de valores, é um modo de vida; enquanto instituição, conforma um regime político e, enquanto práxis, é uma técnica social para compor interesses diversos. Somente pelo exercício permanente do diálogo, da conciliação e do consenso, pilastras da legitimidade, um povo aprende a cultivar a democracia como estilo de vida e a mantê-la como regime político.

A verdadeira práxis democrática, configuradora de um autêntico Estado de Direito, reside principalmente na efetiva concretização dos direitos e garantias fundamentais e não em meras abstrações legais contidas em um texto normativo. Estes direitos e garantias fundamentais, por sua vez, somente ganham vida através do mais afinado instrumento democrático: o processo. Ele, o processo, se constitui no mais valoroso elemento vivificador das aspirações de uma sociedade reprimida de justiça social, pois encontra no irrestrito acesso ao judiciário, no contraditório, na publicidade e na fundamentação os mais altos desígnios da verdadeira democracia. É através dele, o processo, que "os cidadãos revelam ser sujeitos práticos justamente pela práxis: como atores que estão a cada dia dispostos a lutar pela honestidade e pelo tratamento materialmente igual das pessoas no Estado e na sociedade” (MÜLLER, 2003, p. 127).

\section{REFERÊNCIAS}

ARENDT, Hannah. Da revolução. São Paulo: Ática, 1990.

BIDART CAMPOS, German José. Doctrina del Estado Democrático. Buenos Aires: EJEA, 1961.

BOBBIO, Norberto. O futuro da democracia: uma defesa das regras do jogo. 5. ed. Rio de Janeiro: Paz e Terra, 1992.

. Liberalismo e democracia. São Paulo: Brasiliense, 1998. 
BONAVIDES, Paulo. Teoria constitucional da democracia participativa: por um direito constitucional de luta e resistência, por uma nova hermenêutica, por uma repolitização da legitimidade. 2. ed. São Paulo: Malheiros, 2003.

. Do Estado Liberal ao Estado Social. 20. ed. São Paulo: Malheiros, 1994.

CALMON DE PASSOS, Joaquim José. Direito, poder, justiça e processo: julgando os que nos julgam. Rio de Janeiro: Forense, 1999.

CANOTILHO, José Joaquim Gomes. Direito Constitucional. 5. ed. Coimbra: Almedina, 1992.

. Estado de Direito. Lisboa: Gradiva, 1999.

CAPELLETTI, Mauro. Juízes Legisladores? Porto Alegre: S. A. Fabris, 1999.

COSTA, Pietro; ZOLO, Danilo. O Estado de Direito. Trad. por Carlos Alberto Dastoli. São Paulo: Martins Fontes, 2006.

DENTI, Vittorio. Valori costituzionali e cultura processuale. In: SISTEMI e Riforme: Studi sulla giustizia civile. Bologna: Mulino, 1999.

FINLEY, Moses I. Democracia antiga e moderna. Rio de Janeiro: Graal, 1988.

FILARDI, Hugo. Democracia e Processo. Breves Reflexões sobre a influência do Estado Democrático de Direito na prestação da tutela jurisdicional. Revista dos Tribunais, São Paulo, v. 836, p. 83-90, jun. 2005.

GRAU, Eros Roberto; GUERRA FILHO, Willis Santiago. Direito Constitucional, estudos em homenagem a Paulo Bonavides. São Paulo: Malheiros, 2001.

GRINOVER, Ada Pellegrini et al. Participação e Processo. São Paulo: Revista dos Tribunais, 1988.

GROSSI, Paolo. Mitología jurídica de la modernidad. Trad. por Manuel Martínez Neira, Madrid: Trotta, 2003.

KELSEN, Hans. A democracia. 2. ed. São Paulo: Martins Fontes, 2000.

MACPHERSON, Crawford Brough. The life and time of liberal democracy. Oxford: Oxford University Press, 1978.

MOREIRA NETO, Diogo de Figueiredo. Direito da participação política: fundamentos e técnicas constitucionais da democracia. Rio de Janeiro: Renovar, 1992.

MÜLLER, Friedrich. Quem é o povo: A questão fundamental da democracia. 
São Paulo: Max Limonad, 1998.

NALINI, José Renato. O futuro da democracia. Revista de Direito Constitucional e Internacional, São Paulo, n. 38, p. 103-112, jan./mar. 2002.

PICÓ I JUNOY, Juan. Las garantias constitucionales del proceso. Barcelona: Bosch, 1997.

REALE, Miguel. O Estado Democrático de Direito e o conflito das ideologias. São Paulo: Saraiva, 1998.

REIS NOVAES, Jorge. Contributo para uma teoria do Estado de Direito. Coimbra: Coimbra, 1987.

RIBEIRO, Darci Guimarães. La pretension procesal y la tutela judicial efectiva: hacia una teoria procesal del derecho. Barcelona: Bosch, 2004.

. Esboço de uma teoria processual do direito. In: STRECK, Lenio Luiz; MORAIS, José Luis Bolzan de (Org.). Constituição, sistemas sociais e hermenêutica: programa de pós-graduação em Direito da Unisinos: mestrado e doutorado. Porto Alegre: Livraria do Advogado, 2008.

SANTOS, Boaventura de Sousa. Democratizar a democracia: os caminhos da democracia participativa. Rio de Janeiro: Civilização brasileira, 2002.

. Para uma revolução democrática da justiça. São Paulo: Cortez, 2007.

SILVA, José Afonso da. Curso de Direito Constitucional Positivo. 24. ed. São Paulo: Malheiros, 2005.

. O Estado Democrático de Direito. Revista de Direito Administrativo, Rio de Janeiro, n. 173, p. 15-34, jul./set. 1988.

STRECK, Lenio Luiz. Jurisdição constitucional e hermenêutica: uma nova crítica do direito. 2. ed., Rio de Janeiro: Forense, 2004.

STRECK, Lênio Luiz; MORAIS, José Luis Bolzan de. Ciência Política e Teoria do Estado. 5. ed. Porto Alegre: Livraria do Advogado, 2006.

TUCÍDIDES. Historia de la guerra del Peloponeso. Trad. por Juan José Torres Esbarranch. Madrid: Gredos, 2000.

Artigo recebido em 13/03/09 e aceito em 30/07/09 